\title{
Is Recast the Most Effective Type of Corrective Feedback?-Under Cognitive and Sociolinguistic Approach
}

\author{
GU Bing-jie \\ Ningbo Dahongying University, Ningbo, China
}

\begin{abstract}
Currently, there are a variety of researches on corrective feedback, especially on recasts. Most of researches are experiment-based and depend on the certain context. This paper addresses the question of "Is recast the most effective form of corrective feedback?" by two of Second Language Acquisition (SLA) approaches: cognitive approach and sociolinguistic approach. Empirical research will be used as complement. Theoretically speaking, SLA hypotheses in cognitive approach exist disagreements. Interaction hypothesis favors recast while both input hypothesis and output hypothesis doubt the effectiveness of it. Sociolinguistic approach underscores the significance of appropriate and timely corrective feedback and does not give more credit to certain strategy. Both approaches provide the pedagogical implications and elements to take into account for adopting recasts.
\end{abstract}

Keywords: recasts, corrective feedback, cognitive approach, sociolinguistic approach

\section{Introduction}

Corrective, or negative, feedback is a term used to manifest that "an utterance in a learner's language is deviant and that a change or a correction is needed to make it more target-like" (Profozic, 2013, p. 15). Corrective feedback, which implies a clear pedagogical intention, has been widely researched and debated in both Second Language Acquisition (SLA) and Second Language Teaching (SLT). This paper will take the perspective of oral English in classroom-based SLA because verity of definitions on corrective feedback is classroom-based and oral English-focused (Suzuki, 2004; Chaudron, 1977). It also aligns with my role as a teacher-researcher with motivation to adopt corrective feedback in English language teaching class.

There are numerous types of corrective feedback applied in classroom setting, including recast, explicit correction, clarification requests, etc. (Sheen, 2011). The details of types, definitions, and examples are attached in Appendix. The focus of paper is recast. Recast, by definition, is reformulating all or part of the incorrect word or phrase, to show the correct form without explicitly identifying the error (Ellis \& Sheen, 2006). Recast is among the most frequently employed strategies of corrective feedback by teachers and has been the focus of research (Goo, 2012). In the classroom scenario, 60 percent of feedback involved recast regardless of learning contexts and teaching methods (Sheen, 2004). This fact also applies in my case. I use recasts frequently to address students' oral errors. However, is recast the "most effective" type of corrective feedback? Though the question is simple enough, the answer and the question itself can be controversial.

Under the lenses of SLT, the word "effective" can be short uptake time, which means students' immediate response following teacher feedback (Suzuki, 2004), or the improvement in the target language learning which

GU Bing-jie, master, School of Humanities, Ningbo Dahongying University. 
may be reflected in the test scores. It also depends on the area of language or on the specific linguistic feature of language (Nicholas, Lightbown, \& Spada, 2001). Beyond that, the long-term effects on learners' second language development can also be one of dimensions, which has often been neglected due to the certain time span. More importantly, different learning contexts will produce different results. It is undeniable that the results for above criteria are usually based on the empirical study. At the same time, different linguistic approaches, such as cognitive linguistics and sociolinguistics, provide different pathways to analyze this question in the theoretical way, which may lead to different results. Specifically in my case, my own practice in the language teaching class may produce another result. Generally speaking, researchers are cautious about making direct connections between theory, empirical research, and real teaching practice (VanPattern \& Williams, 2008, p. 190), which adds the complexity to answer this question. Last but not least, it is still not clear how crucial corrective feedback is when compared to all the other influents in SLT, even if recast is "the most effective" one in corrective feedback.

In this paper, two linguistic approaches - cognitive linguistics and sociolinguistics-are adopted to analyze the function and effectiveness of recasts in corrective feedback, which directly or indirectly address the question proposed and guide my in-class practice. The results of empirical research using diverse research methods will also be discussed as complement. The assumptions underlying each approach should first be emphasized. One major hypothesis as guiding the cognitive linguistic approach to language is knowledge of language emerges from language use (Croft \& Cruse, 2004, p. 25). It is a usage-based approach contains that the purpose of language is communication (Tyler, 2012). Under the cognitive linguistics spectrum, there are input hypothesis, interaction hypothesis, noticing hypothesis, output hypothesis, etc., which are consistent with the learning stages in SLA, from input and intake to output (Leow, 2015, p. 69). In terms of sociolinguistic approach, the basic assumption is that all cognitive development, including language development, occurs as a result of social interactions between individuals (Sheen, 2011, p. 27). In addition, learning is thought to occur when an individual interacts with an interlocutor within his or her zone of proximal development (ZPD) (Clapper, 2015), which is also one of the key terms in sociolinguistics. The detailed analysis is as followings.

\section{Recasts Under Cognitive Linguistic Approach}

Recast is fundamentally a concept grounded in cognitive linguistics. According to cognitive linguist Michael Long (2011, speech), who proposed interaction hypothesis and advocates for the benefits of recasts, corrective feedback provides especially advantageous opportunities for explicit learning and recasts, in particular, are crucial points at which explicit and implicit learning combine in optimal ways. However, interaction hypothesis is problematic itself which will be discussed later and the other hypotheses in cognitive linguistics listed in the introduction part will be adopted to analyze recasts, which will lead to the various conclusions.

\section{Input Hypothesis}

Krashen's input hypothesis involved in the first learning stage. Based on input hypothesis, corrective feedback in general contributes little for learners' second language development since "comprehensible input serving as positive evidence is sufficient to acquire a second language" (Krashen, 1981, p. 160). Content-based teaching method is directly hinged to this hypothesis. In the experimental study conducted by Lyster and Ranta (1997), they found recasts, which are most widely used in the content-based French immersion classes, are less 
likely to raise students' notice and student uptake was least likely to occur after recasts, though recasts are input-providing corrective feedback strategy according to Ellis (2007). They explained that these students failed to be aware of recasts and perceive them as "echo". The reason underpinning is probably that students in this experiment are at primary level and they have an orientation to meaning making. The French-speaking context should also be taken into account.

\section{Interaction Hypothesis}

Long (1991)'s interaction hypothesis is the development of Krashen's input hypothesis. Long asserts that "interlocutors' attempts to make their speech comprehensible will result in the negotiation for meaning characterized by modifications in the interactional structure on conversation" (p. 201). According to Long (1996) in the revised model of interaction hypothesis, corrective feedback is critical for acquisition and recasts, one of the strategies involved in the negotiation for meaning, is the best candidate for focusing attention on form because they connect "input, internal learner capacities, particularly selective attention, and output in productive ways" (p. 55). To balance the relationship between both terms (negotiation for meaning and focus on form), Long (1991) defined focus-on-form as "an instructional intervention that overtly draws students attention to linguistic elements as they arise incidentally in lessons whose overriding focus is on meaning or communication". Given the above background and definition, it should be noted that Long has requirement for both students and teachers as the prerequisite to make recasts effective. Students are supposed to jointly attend to form and meaning while negotiating meaning (Long, 2006). For teachers, they are obliged to draw students' attention to linguistic elements. Attention is an essential component of cognition. In this sense, this hypothesis failed to consider students' differences and learning objectives. But it can guide the SLT practice in general.

Empirically speaking, the interaction hypothesis has witnessed an increasing number of research and it is now commonly accepted within the SLA literature that there is a robust connection between interaction and learning (Gass \& Mackey, 2007). In terms of corrective feedback and recasts in particular, Ellis, Basturkmen, and Loewen (2001) observed that intermediate learners immediately reacted to most of these recasts in communicative ESL (English as a Second Language) classes, which is the natural home for Focus-on-Form, and learners respond to recasts in ways that may contribute positively to their second language development. Long (1998)'s one of frequently-cited researches demonstrates that participants hearing recasts scored statistically significantly higher than those hearing models and claims that "recasts play a facilitative role in L2 acquisition" (p. 87). The subjects in both experiments are adult learners, rather than primary school students as indicated in Lyster and Ranta's experiment earlier. It is safe to say that adults are inclined to attend to form while young learners are more meaning-oriented. This age-related variation under sociolinguistic approach partly accounts for the different results.

However, the most obvious drawback is that there is little proof of its importance to second language learning rather than to second language comprehension (Cook, 2008, p. 134). Secondly, it is usually not clear whether or not recasts are conversational as Long desires (Sheen, 2011, p. 23). Specifically speaking, recasts can be roughly put into two categories: One is didactic recast and another one is conversational recast. In the real classroom setting, didactic recasts are more commonly used as communication problems only seldom arise. Thirdly, language teachers in the SLT classrooms usually speak the same language as the students and they would resort to code switching, which is a concept under sociolinguistics as well. It also reflected the 
widespread problem of most SLA theories - theory-makers do not speak the first language of their subjects and the applicability in the real scenario can be doubtable.

\section{Noticing Hypothesis}

Schmidt's noticing hypothesis $(1991,2001)$ is the first theoretical postulation in the SLA field to define the role of attention in direct connection with the construct of awareness at the early input-to-intake stage (Leow, 2015, p. 69). He suggests that nothing is learned unless it has been noticed and noticing is the indispensible starting point in acquisition (Lightbown \& Spada, 2013, p. 115). In terms of the relationship between awareness and notice, it should be noted that one can pay attention to an item in the input, but this does not always translate to it being noticed (Leow, 2015, p. 160), which indicates that noticing hypothesis goes further than interaction hypothesis in terms of $\mathrm{L} 2$ learning process.

Based on noticing hypothesis, corrective feedback, which works by helping learners to notice the gap between interlangauge forms and target forms, can be viewed as a form of input enhancement (Smith, 1991), which raises students' awareness of the motivated elements of the target language (Littlemore, 2009, p. 187). In regard to the comparison of different corrective feedback forms, the general pattern of results indicates that more explicit one lead to larger gains (Ortega, 2009, p. 75). In this sense, recasts, which are forms of implicit corrective feedback, definitely not the most effective one when compared with the explicit forms of feedback, such as metalinguistic explanations. However, the explicitness of recasts, which is defined as "the perceptual salience and linguistic marking to make the corrective intent clear to learners" (Sheen, 2006, p. 378), can be convertible. To make recasts more explicit, one can adopt exaggerated intonation, excessive use of gesture, slowing down, and repetition (Littlemore, 2009, p. 187). Shorter recasts, those closer to the trigger utterance and those that change the utterance in few ways can be effective too (Philp, 2003). All these practice guides teachers' adoption of recasts in classroom settings.

\section{Output Hypothesis}

Swain's output hypothesis is the only theoretical postulation in SLA that is directed at stage five of the learning process (Leow, 2015, p. 90). According to Swain (1995), output plays major roles in language acquisition including noticing, hypothesis testing, and reflective functions. In this regard, the ones encourage self-repair or output prompting, which includes elicitation and clarification requests, and are more effective than recasts, which do not require learners to undertake self-repair. However, Krashen (1998) noted that encouraging learners to produce the target language correctively in front of the class inhibits acquisition since it arouses anxiety level in the leaner. Individual anxiety level in classroom setting also belongs to sociolinguistic category. Additionally, Swain (2005) adopts a socio-cultural perspective in her revised version highlights the significance of teacher-learner dialogues in promoting acquisition (Walsh, 2006, p. 19).

\section{Recasts Under Sociolinguistic Approach}

Several sociolinguistic concepts, including age variation, code-switching, and anxiety level, have been listed above to point out the drawbacks of the SLA hypotheses in cognitive approach. Fundamentally, cognitive SLA approach has been criticized for its overly narrowed view towards classroom interaction (Donato, 2000) and it ignores the social dimension of learning (Firth \& Wagner, 2007). When the same question of "Are recasts the most effective corrective feedback forms?" was asked under sociolinguistic approach, the answer is much more vague since its main concern is when and how corrective feedback in an L2 classroom is 
appropriate and timely (Rassaei, 2014a). Key concepts part explained the reason of the complexity and the research implication part followed provides the general guideline for teachers to consider from sociolinguistic perspective.

\section{Key Concepts in Sociolinguistics}

Theoretically speaking, Vygotsky, the most prominent sociolinguist, underscored three key concepts, which serve as guidelines for comparing corrective feedback forms: social nature of knowledge, zone of proximal development, and scaffolding (Verschueren, 2012). First, in terms of social nature, learning occurs in the first instance through interaction with others (Seedhouse, 2004). It should be noted that "greater importance is attached to the conversations themselves with learning occurring through the social interaction", which is classroom context in this case. Second, ZPD, as mentioned in the introduction part, is "the distance between the actual development level as determined by individual linguistic production, and the level of potential development as determined through language produced collaboratively with a teacher or peer" (Ohta, 2001, p. 32). The various social contexts and highlighted individual differences indicate that the general picture of corrective feedback comparison cannot be drawn. Meanwhile, the scope of recasts is broadened to include students to students. Third, scaffolding is a collaborative process through which a teacher or a more proficient learner provides support or guidance to assist a less proficient learner. Scaffolding feedback, which is derived from sociolinguistics, engages learners in correcting their non-target-like forms in a collaborative manner (Rassaei, 2014b). In this sense, only by providing learners with scaffolding that beyond the current language level appropriately can recasts get its effects.

To conclude the above analysis, classroom context and individual difference have to be taken into account in analysis of the effectiveness of recasts. It focuses on how assistance from a teacher or a more expert peer can help learners exceed their current level of development (Rassaei, 2014b).

\section{Implications From Researches}

When compared with cognitive approach, sociolinguistic approach usually involves comparative research to address the question of effectiveness, such as influence of teaching methodology, impact of classroom dynamics, and students' preference. The subjects in these studies are limited in number and contexts varied sharply. So, it is unwise to make overgeneralization but rule-of-thumb can be derived from.

In Llinares and Lyster (2014)'s research, recasts occurring more frequently than prompts and explicit correction in both content-based language teaching (CBLT) and immersion classrooms. However, recasts were much more effective than either prompts or explicit correction at leading to immediate repair in CLIL (Content and Language Integrated Learning) classrooms. To be specific about immersion classroom, recasts are least effective in terms of promoting students' immediate repair in French immersion (FI) classrooms, while the three corrective feedback strategies all led to similar proportions of repair in Japanese immersion (JI) classrooms. It is because that the CLIL teachers seemed to be more conscious of the language aspect, using didactic recasts, which are more explicit, and avoiding conversational recasts, which are more implicit. This finding aligns with the analysis in cognitive approach. It should be pointed out this research oversimplified the real classroom situations, which also involves teacher-student relationship, students' perception, etc., beyond teaching methodologies.

In Morris and Tarone (2003)'s classroom dynamics research, they found that the attention learners paid to corrective feedback would be influenced by their social relationship with their interlocutors. Except from 
linguistic message provided in recasts, social message, which can be exampled as a bad-tempered peer who provides recast, should not be neglected. It will have a negative influence on learners' perception and indirectly undermine the effectiveness of recasts. In terms of learners' preferences for corrective feedback, Yoshida (2008) argues that ideally, learners were likely to prefer being given sufficient time to think about the correct answer after an error rather than being provided with correct forms by recasts, but from a social perspective, it takes time and might trigger social embarrassment if they cannot provide proper answers. In addition, proficiency level is directly related to effectiveness of implicit corrective feedback according to Lee (2013). In Kaivapanah and Vlavi (2015)'s research, it is found that "more proficient learners tend to favor more elicitative types of feedback that required self-correction" and students at all language proficiency prefer peer feedback, which is contradicted to teachers' attitude. To combine the research results listed, socially speaking, classroom dynamics, possible strain caused by corrective feedback, and students' preference should be take into account in regard to effective corrective feedback.

\section{Conclusion}

This paper tried to address the research question of "Is recast the most effective strategy among corrective feedback?" from two linguistic approaches. Theoretically speaking, SLA hypotheses in the cognitive approach exists disagreements. Interaction hypothesis favors recast while both input hypothesis and output hypothesis doubt the effectiveness of it. Noticing hypothesis offers the pedagogical practices to enhance explicitness of recasts as input enhancement. Sociolinguistic approach underscores the significance of appropriate and timely corrective feedback and does not give more credit to certain strategy.

The research conducted in both approaches provides the pedagogical implications and elements to take into account for adopting recasts. But comparative study and social factors are generally missing in cognitive approach. The highlighted importance of learner's awareness towards the recasts is applicable regardless of the contexts. For social factors, teaching methods, classroom dynamics, individual anxiety level, and students' preference are variables for teachers to consider.

\section{References}

Blommaert, J. (2012). Sociolinguistics and English language studies. In B. Street and C. Leung (Eds.), Handbook of English language studies (pp. 1-17). London: Routledge.

Chaudron, C. (1977). A descriptive model of discourse in the corrective treatment of learners' errors. Language Learning, 27, $29-46$.

Clapper, T, C. (2015). Cooperative-based learning and the zone of proximal development. Theory to Practice in Simulation, 46(2), 148-158.

Cook, V. (2008). Second language learning and language teaching. London: Hodder Education.

Croft, W., \& Cruse, A. (2004). Cognitive linguistics. New York: Cambridge University Press.

Donato, R. (2000). Sociocultural contribution to understanding the foreign and second language classroom. In J. Lantolf (Ed.), Sociocultural theory and second language learning (pp. 27-50). Oxford: Oxford University Press.

Ellis, R. (2007). Corrective feedback in theory, research and practice. Papers presented at The 5th International Conference on ELT in China \& the 1st Congress of Chinese Applied Linguistics, Beijing, China.

Ellis, R., \& Sheen, Y. (2006). Reexamining the role of recasts in second language acquisition. SSLA, 28, 575-600.

Ellis, R., Basturkmen, H., \& Loewen, S. (2001). Learner uptake in communicative ESL lessons. Language Learning, 51(2), 231-318.

Firth, A., \& Wagner, J. (2007). Second language learning as a social accomplishment: Elaborations on a reconceptualized SLA. The Modern Language Journal, 91, 800-829. 
Gass, M. S., \& Mackey, A. (2007). Input, interaction, and output in second language acquisition. In B. Vanpatten and J. Williams (Eds.), Theories in Second Language Acquisition (pp. 179-199). London: Routledge.

Goo, J. (2012). Recasts in the acquisition of English relative clauses: Positive or negative evidence? Studies in English Education, $17(2), 203-220$.

Kaivanpanah, S., \& Alvai, M. S. (2015). Preferences for international feedback: Differences between learners and teachers. The Language Learning Journal, 43, 74-93.

Krashen, S. (1981). Aptitude and attitude in relation to second language acquisition and learning. In K. C. Diller (Ed.), Individual differences and universals in language learning aptitude (pp. 155-175).

Lee, E. (2013). Corrective feedback preferences and learner repair among advanced ESL students. System, 41, 217-230.

Leow, P. R. (2015). Explicit learning in the L2 classroom. London: Routledge.

Lightbown, M. P., \& Spade, N. (2013). How languages are learned. Oxford: Oxford University Press.

Littlemore, J. (2009). Applying cognitive linguistics to second language learning and teaching. London: Palgrave Macmillan.

Llinares, A., \& Lyster, R. (2014). The influence of context on patterns of corrective feedback and learner uptake: A comparison of CLIL and immersion classrooms. The Language Learning Journal, 42, 181-194.

Loewen, S., \& Philp, J. (2006). Recasts in the adult English L2 classroom: Characteristics, explicitness, and effectiveness. The Modern Language Journal, 90, 536-556.

Long, M. (1991). Focus on form: A design feature in language teaching methodology. In K. De Bot, R. Ginsberg, and C. Kramsch (Eds.), Foreign language research in cross-cultural perspective. Netherlands: John Benjamins.

Long, M. (1996). The role of the linguistic environment in second language acquisition. In W. R. Ritchie and T. J. Bhatia (Eds.), Handbook of second language acquisition. San Diego: Academic Press.

Long, M. (2006). Recasts in SLA: The story so far. In M. Long (Ed), Problems in SLA (pp.75-116). Mahwah: Lawrence Erlbaum.

Lyster, R., \& Ranta, L. (1997). Corrective feedback and learner uptake: Negotiation of form in communicative classrooms. Studies in Second Language Acquisition, 19(1), 37-61.

Morris, A. F., \& Tarone, E. E. (2003). Impact of classroom dynamics on the effectiveness of recasts in second language acquisition. Language Learning, 53, 325-368.

Nicholas, H., Lightbown, M. P., \& Spada, N. (2001). Recasts as feedback to language learners. Language Learning, 51(4), $719-758$.

Ohta, A. (2001). Second language acquisition processes in the classroom. Mahwah, NJ: Erlbaum.

Ortega, L. (2009). Understanding second language acquisition. London: Routledge.

Philp, J. (2003). Constraints on "noticing the gap": Non-native speakers' noticing of recasts in NS-NNS interaction. SSLA, 25, 99-126.

Profozic, M. N. (2013). The effectiveness of corrective feedback and the role of individual difference in language learning: A classroom study. Germany: Peter Lang.

Rassaei, E. (2014a). Oral corrective feedback, foreign language anxiety and L2 development. System, 49, 98-109.

Rassaei, E. (2014b). Scaffolded feedback, recasts, and L2 development: A sociocultural perspective. The Modern Language Journal, 98, 417-431.

Schiffrin, D. (2005). Interactional Sociolinguistics. In S. L. McKay and N. H Hornberger (Eds.), Sociolinguistics and language Teaching (pp. 307-328). Cambridge: Cambridge University Press.

Schmidt, R. (1991). The role of consciousness in second language learning. Applied Linguistics, 11, 129-158.

Schmidt, R. (2001). Attention. In P. Robinson (Ed.), Cognition and second language instruction (pp. 3-32). New York: Cambridge University Press.

Seedhouse, P. (2004). The interactional architecture of the language classroom: A conversation analysis perspective. Oxford: Blackwell.

Sheen, Y. (2004). Corrective feedback and learner uptake in communicative classrooms across instructional settings. Language Teaching Research, 8(3), 263-300.

Sheen, Y. (2006). Exploring the relationship between characteristics of recasts and learner uptake. Language Teaching Research, 10, 361-392.

Sheen, Y. (2011). Corrective feedback, individual differences and second language learning. London: Springer.

Smith, M. S. (1993). Input enhancement in instructed SLA. Studies in Second Language Acquisition, 15(2), 165-179.

Suzuki, M. (2004). Corrective feedback and learner uptake in adult ESL classrooms. Columbia University Working Papers in TESOL \& Applied Linguistics, 4(2). 
Tyler, A. (2012). Cognitive linguistics and second language learning. London: Routledge.

VanPattern, B., \& Williams, J. (2008). Theories in second language acquisition. London: Routledge.

Verschueren, J. (2012). Ideology in language use: Pragmatic guidelines for empirical research. Cambridge, New York: Cambridge University Press.

Walsh, S. (2006). Investigating classroom discourse. London: Routledge.

Yoshida, R. (2008). Teachers' choice and learners' preference of corrective feedback types. Language Awareness, 17, 78-93.

Appendix

Table 1

Corrective Feedback Types (Lee, 2013)

\begin{tabular}{|c|c|c|}
\hline CF types & Definition & Example \\
\hline 1. Explicit correction & $\begin{array}{l}\text { Indicates an error has been committed, identifies the error, } \\
\text { and provides the correction. }\end{array}$ & $\begin{array}{l}\text { S: On May. } \\
\text { T: Not on May, In May. } \\
\text { We say, "It will start in May." }\end{array}$ \\
\hline 2. Recast & $\begin{array}{l}\text { Reformulates all or part of the incorrect word or phrase, } \\
\text { to show the correct form without explicitly identifying the error. }\end{array}$ & $\begin{array}{l}\text { S: I have to find the answer on the book? } \\
\text { T: In the book }\end{array}$ \\
\hline 3. Clarification request & $\begin{array}{l}\text { Indicates that the student's utterance was not understood } \\
\text { and asks that the student reformulate it. }\end{array}$ & $\begin{array}{l}\text { S: What do you spend with your wife? } \\
\text { T: What? (Or, Sorry?) }\end{array}$ \\
\hline 4. Meta-linguistic feedback & $\begin{array}{l}\text { Gives technical linguistic information about the error } \\
\text { without explicitly providing the correct answer. }\end{array}$ & $\begin{array}{l}\text { S: There are influence person who. } \\
\text { T: Influence is a noun. }\end{array}$ \\
\hline 5. Elicitation & $\begin{array}{l}\text { Prompts the student to self-correct by pausing so the } \\
\text { student can fill in the correct word or phrase. }\end{array}$ & $\begin{array}{l}\text { S: This tea is very warm. } \\
\text { T: It's very...? } \\
\text { S: Hot. }\end{array}$ \\
\hline 6. Repetition & $\begin{array}{l}\text { Repeats the student's error while highlighting the error } \\
\text { or mistake by means of emphatic stress. }\end{array}$ & $\begin{array}{l}\text { S: I will showed you. } \\
\text { T: I will SHOWED you? } \\
\text { S: I'll show you. }\end{array}$ \\
\hline
\end{tabular}

